\title{
Data Reconciliation on PLTGU Gresik Using Particle Swarm Optimization (PSO)
}

\author{
Wahyu T. Pratiwi ${ }^{1}$, Totok R. Biyanto ${ }^{1}$
}

\begin{abstract}
The innaccurate on process data in PLTGU Gresik does not satisfy the mass and energy balance. Data reconciliation techniques can effectively improve precision and reduce measurement error on process variable estimation of data plant through modeling and optimization techniques. In this paper, we propose PSO (Particle Swarm Optimization) algorithm to solve the data reconciliation problem for precise improvement and error minimization. As a result, the standard deviation of data measurement and reconciliation is different on each variable heat exchanger component, so that indicates random errors on measurement. Based on the result, PSO algorithm is capable generate reliable data and minimizing error with sum square error is equal to 1.153. It means PSO algorithm is compatible with the instrument system on PLTGU Gresik. Moreover, data reconciliation is applied then followed with detection gross error using statistical test that is Global Test. As the result, there is not gross error on the measurement.
\end{abstract}

Keywords—Data reconciliation, particle swarm optimization, detection gross error.

\section{INTRODUCTION}

A ccurate process data is important to evaluate the performance of process operation and to justify the process mass and energy balances [1]. Accurate data in operation will provide efficient, profitable, and safe plant performance that it can be indicated from the plant measurement. Each component has a specific accuracy, so it gave rise to inconsistency data in the instrument system. Based on raw data of PLTGU Gresik, there is a inconsistent and inaccurate process which is not satisfy mass and energy balances. However, it can be reduced by using more accurate instrumentation, calibration, and data reconciliation.

Data reconciliation is a technique for data processing to improve the accuracy, precision and reliability of process data [2], [3]. A motivation to apply data reconciliation to reduce imprecision and unreliability measurement data and to complete the unmeasured data. Data reconciliation techniques have two main components, e.g modeling and selection optimization processes. Data reconciliation have been widely used in the power plant [4]-[6], on gas turbines and combined cycle ower generation units [7] and coalfired generation units [8]-[10]. In this paper, we will present data reconciliation on the power plant of heat exchanger component, which is preheater, low pressure economizer (LP Eco), high pressure economizer 1 (HP Eco 1), low pressure evaporator (LP Eva), high pressure economizer 2 (HP Eco 2), high pressure evaporator (HP Eva), high pressure superheater 1 (HP SH 1), and high pressure superheater 2 (HP SH 2) which is satisfy the mass and energy balance in steady state condition.

In previous study, data reconciliation has also been applied with use linear multiple regression model [11]. This model depends on redundancy. In this case, if this model is

\footnotetext{
${ }^{1}$ Wahyu T. Pratiwi and Totok R. Biyanto are with Department of Physics, Institut Teknologi Sepuluh Nopember, Surabaya, 60111, Indonesia. E-mail: wahyu.t.pratiwi@gmail.com; trb@ep.its.ac.id;
}

used on more complex plants, it will be generate the less optimal results. It leads to the low result of calculation to gross error detection. In another previous study, Correntropy based Nonlinear Dynamic Data Reconciliation (CNDDR) [1]. Based on the result, this model can reduce the effect of gross error. Gross Error Detection and Identificaion (GEDI) can be clasified based on the type of gross erros from measurement. Nevertheless, the CNDDR parameters have an influence to data reconciliation performance, such as the size of history data, scale process system measurement, and definiton initial solution. In another reason, the process model that has a high accuracy with unknown parameters must be determine through measurement data. Nondeterministic optimization algorithm (stochastic) [12] like Particle Swarm Optimization (PSO) is perfect method to solve data reconciliation problem in actual industrial data of polypropylene reactor in real time. As a result, PSO is successfully to generate reliable information in real time application. Eventhough, this work is not performed sequentially about detection gross error. Hence, the presence of gross error was unknown.

In this work, we will solve the steady state data reconciliation problem in more complex plant, which is consist of eight heat exchanger components that using PSO algorithm. Particle Swarm Optimization (PSO) optimization method was proposed to solve the data reconciliation problem. Application of PSO is based on the search direction (vector) and does not depend on computation of derivates to make prediction nor depend on any sort of numerical manipulation of the objective function [11]. This technique will be faster to achieve the goal and to reach global optimum if the process is a nonlinear process.

The complex plant in PLTGU Gresik has counter flow rate between hot and cold fluids, where the hot fluids flow comes from lower side and the cold fluids flow comes from upper side. Therefore, to achieve balance condition, the top component (the first component), preheater receive cold 
fluid first have to wait for the flow of hot fluid from the bottom of the high pressure superheater 2 component. This flow is continuing for the both fluids, where the cold fluids must be through from the preheater to the last component (HP SH 2), otherwise for the hot fluids must be through from the high superheater 2 ( $\mathrm{HP} \mathrm{SH} 2$ ) to the first component (preheater).

Steady state reconciliation is carried out using variables measured in the process. The purpose is to evaluate the measurement of uncertainty by using the direct method [13] or by using indirect methods [14], [15]. Another method also used flow diagram based on mass and energy balance [16].

Implementation of data reconciliation becomes more complex when the gross error present in measurement [16]. Data reconciliation and gross error detection are performed sequentially [6]. Gross error detection is required due to the ability to identify the bias of measurement [1]. Gross error is declared with statistical test model that must be able to identify type, location, and quantity of gross error [17]. In this work, we use Global Test to detect gross error. In previous study, Global Test was applied to detect gross error on microturbin application [7], [8], [18].

Based on the above explanation, the implementation of reconciliation data will be demonstrated on heat exchanger component. Therefore, this work will focus on data reconciliation in PLTGU Gresik using particle swarm optimization (PSO) and sequentially gross error detection. In this research, PSO is expected to solve data reconciliation problems optimally.

\section{METHOD}

\section{A. Data Collection}

In this work, raw data is taken from the plant on January 2017, which there is six data in each day. Thus, the overall raw data from the plant is 1488 data that consists of five variables for each component. Data collection is based on eight heat exchanger components in boiler.

\section{B. Variable Identification}

In this case, to calculate the mass and energy balance as a constrain, it requires mass flow rate and temperature as variable reconciliation from shell and tube side. In the other, variable temperature consist of inlet temperature for cold $\left(\mathrm{T}_{\mathrm{C} . \text { in }}\right)$ dan hot $\left(\mathrm{T}_{\mathrm{H} . \mathrm{in}}\right)$ and outlet temperature for cold $\left(\mathrm{T}_{\mathrm{C} \text {.out }}\right)$ and hot $\left(\mathrm{T}_{\text {H.out }}\right)$ and mass flow rate cold $\left(\mathrm{m}_{\mathrm{C}}\right)$ and hot $\left(\mathrm{m}_{\mathrm{H}}\right)$. Table 1 showed that data availability of heat exchanger component.

Based on raw data in Table 1, there is variable was not observed or unmeasured. To complete the unmeasured data, we must be calculate with equation that following mass and energy balance, in equation (1). The variable of mass flow rate for hot fluid is not a variable reconciliation because it has constant value. As a result, variable reconciliation consist of five variable, that is inlet temperature for cold ( $\left.\mathrm{T}_{\mathrm{C} . \text { in }}\right)$ dan hot $\left(\mathrm{T}_{\mathrm{H} . \mathrm{in}}\right)$ and outlet temperature for cold $\left(\mathrm{T}_{\mathrm{C} . \mathrm{out}}\right)$ and hot $\left(\mathrm{T}_{\text {H.out }}\right)$ and mass flow rate cold $\left(\mathrm{m}_{\mathrm{C}}\right)$.
TABLE 1.

AVAILABILITY DATA

\begin{tabular}{lllllll}
\hline \hline Component & $\boldsymbol{m}_{\mathrm{C}}$ & $\mathbf{T}_{\text {C.in }}$ & $\mathbf{T}_{\text {C.out }}$ & $\boldsymbol{m}_{\mathbf{H}}$ & $\mathbf{T}_{\text {H.in }}$ & $\mathbf{T}_{\text {H.in }}$ \\
\hline Preheater & $\sqrt{ }$ & $\sqrt{ }$ & $\sqrt{ }$ & $\sqrt{ }$ & $\sqrt{ }$ & $\sqrt{ }$ \\
LP Eco & $\sqrt{ }$ & $\sqrt{ }$ & $\mathbf{X}$ & $\sqrt{ }$ & $\sqrt{ }$ & $\sqrt{ }$ \\
HP Eco 1 & $\sqrt{ }$ & $\sqrt{ }$ & $\mathbf{X}$ & $\sqrt{ }$ & $\sqrt{ }$ & $\sqrt{ }$ \\
LP Eva & $\sqrt{ }$ & $\sqrt{ }$ & $\mathrm{X}$ & $\sqrt{ }$ & $\sqrt{ }$ & $\sqrt{ }$ \\
HP Eco 2 & $\mathrm{X}$ & $\mathrm{X}$ & $\mathrm{X}$ & $\sqrt{ }$ & $\sqrt{ }$ & $\sqrt{ }$ \\
HP Eva & $\mathrm{X}$ & $\sqrt{ }$ & $\mathrm{X}$ & $\sqrt{ }$ & $\sqrt{ }$ & $\sqrt{ }$ \\
HPSH 1 & $\mathrm{X}$ & $\mathrm{X}$ & $\mathrm{X}$ & $\sqrt{ }$ & $\sqrt{ }$ & $\sqrt{ }$ \\
HPSH 2 & $\mathrm{X}$ & $\mathrm{X}$ & $\sqrt{ }$ & $\sqrt{ }$ & $\sqrt{ }$ & $\sqrt{ }$ \\
\hline \hline
\end{tabular}

\section{Modeling Plant}

Based on Table 1, there is unmeasured variable. So, it will be first calculated through mass and energy balance equation, like equation (1). In Figure 1, the plant of heat exchanger is reported.

The heat exchanger performance must satisfy the law of mass and energy balance on the steady state condition. In generally, it is using driving force that is Log Mean Temperature Difference (LMTD). Due to the assumption that loses energy is neglected; the heat energy from hot fluids equal to heat energy from cold fluids. So, that is

$$
\begin{aligned}
& Q_{C . i k}=Q_{H . i k} \\
& \dot{m}_{H . i k} C_{P H i k} \cdot\left(T_{H . o u t . i k}-T_{H . i n . i k}\right) \\
& =\dot{m}_{C . i k} . C_{P C . i k}\left(T_{C . i n . i k}-T_{\text {C.out.ik }}\right)
\end{aligned}
$$

Where is:

$Q_{c . i k}=$ Amount of heat energy that is getting by cold fluids to i-component on the k-data

$Q_{h . i k}=$ Amount of heat energy that is losing by hot fluids on i-component in the $\mathrm{k}$ - data

$\dot{m}_{H . i k}=$ Mass flow rate for hot fluids on i-component in the k-data

$\dot{m}_{C . i k}=$ Mass flow rate for cold fluids on i-component in the k-data

$C_{P H . i k}=$ Heat specific for hot fluids on i-component

$C_{P C \text {.ik }}=$ Heat specific for cold fluids on $\mathrm{i}$-component

$T_{\text {H.in.ik }}=$ Inlet temperature for hot fluids on i-component in the k- data

$T_{\text {H.out.ik }}=$ Outlet temperature for hot fluids on icomponent in the $\mathrm{k}$ - data

$T_{\text {C.in.ik }}=$ Inlet temperature for cold fluids on icomponent in the $\mathrm{k}$ - data

$T_{\text {C.out.ik }}=$ Outlet temperature for cold fluids on icomponent in the $\mathrm{k}$ - data

Based on Figure 1, steam flow from preheater outlet will be divided into two flows to each LP Eco and HP Eco 1 inlet. It comprise $0.272 m_{C . P}$ for LP Eco and $0.728 m_{C . P}$ for HP Eco 1 (where is $m_{C P}$ is mass flow rate of preheater). Unmeasured variable calculated by equation of mass and energy balance to fill the missing raw data. The value of the specific heats depend on temperature in each component. The specific heat of each data ( $\mathrm{C}_{\mathrm{PH} . \mathrm{i}}$ and $\mathrm{C}_{\mathrm{PC} . \mathrm{i}}$ ) in this article are assumed to be independent of temperature by selecting average temperature value from data collecting of each component in nominal range of temperature variations. Therefore, $\mathrm{C}_{\mathrm{PH} . \mathrm{i}}$ and $\mathrm{c}_{\mathrm{pC} . \mathrm{i}}$ have the same value for each data in the same components that showed in Table 2. 


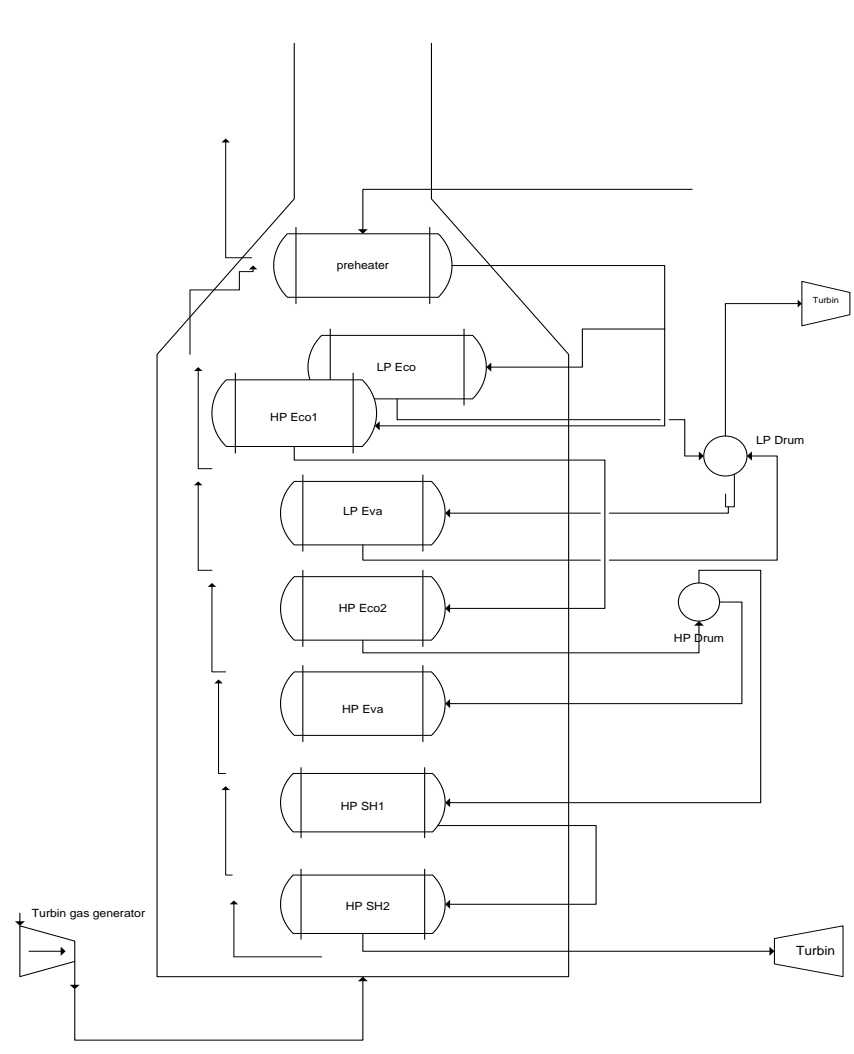

Figure 1. Heat exchanger component

TABLE 2.

THE VALUE OF CPH AND CPC

\begin{tabular}{lcc}
\hline Component & Temp. for cold fluid & Temp. for hot fluid \\
\hline Preheater & 1.09 & 1.017 \\
LP Eco & 1.45 & 1.022 \\
HP Eco 1 & 1.5 & 1.022 \\
LP Eva & 5.15 & 1.034 \\
HP Eco 2 & 1.89 & 1.047 \\
HP Eva & 4.89 & 1.076 \\
HPSH 1 & 3.7 & 1.089 \\
HPSH 2 & 2.98 & 1.089 \\
\hline
\end{tabular}

\section{Data Reconciliation}

Data reconciliation is first proposed by Kuehn and Davidson (1961) [11]. The aim of data reconciliation is to solve optimization problem through minimizing error about measurement and estimate variable with respecting constraint in process model, such as the law of mass and energy balance. The application of data reconciliation is also used for complementing some methods to improved estimation in plant, such as process monitoring [7]; plant simulation [19]; advanced process control [20]; or real time optimization [3].

On process industry, measurements on steady state actually never reached because the presence of noise that will continue to appear in accordance with changing condition [17]. Therefore, by applying data reconciliation to the state of steady state, good results are obtained with small dynamic variations in the process. The problem of data reconciliation on steady state condition is formulated in an equation of least square minimization [21] as follow: $\min _{x, u} \gamma=(\mathbf{x}-\hat{\mathbf{x}})^{T} \Sigma^{-1}(\mathbf{x}-\hat{\mathbf{x}})=\sum_{i=1}^{n} \frac{\left(\mathbf{x}_{\mathbf{i}}-\hat{\mathbf{x}}_{\mathbf{i}}\right)^{2}}{\sigma_{i}^{2}}$

With $\mathbf{f}(\hat{\mathbf{x}}, \mathbf{y})=0$

Where is:

$\gamma$ : Objective function

$x_{n x}$ : Measured value of measured parameters with matrix $n$ x 1

$\hat{x}_{n x}$ : Reconciled value measured parameters with matrix n x 1

$\sigma_{i}:$ Estimated error standard deviation

$\mathrm{f} \quad$ : Steady state system constraint equation $\mathrm{m} \times 1$

$\mathrm{y}$ : Calculated value of unmeasured parameters matrix p x 1

$\Sigma$ : Estimated covariance matrix of measured data matrix q x 1

Data reconciliation can be applied with respecting constraint if the value of unmeasured parameter (p) is less than the value of constrain $(\mathrm{m})$. The constraint equation such as mass and energy balance must satisfy the actual value from measured parameter. In this work, we use PSO algorithm to solve reconciliation problem. The reconciliation result contains $\hat{x}_{n \times 1}$ for measured parameter, $\mathbf{y}_{n \times 1}$ for unmeasured parameter by using maximum tolerance limits for temperature of 1 degree and mass flow rate of $5 \%$.

Optimization technique with PSO algorithm is first proposed by Kennedy and Ebrhart [22] that get inspired from the circulation of social information and behavior that observed in a swarm to show global optimization algorithm. Furthermore, the result is optimum solution showed as a point in multidimensional space (real-valued optimization). PSO algorithm is based on social behavior that is every individual action influenced by other individual action in a population, such as birds, fish, and bees. Every individual of population was called a particle. Swarm algorithm can generate low cost, more fast and robust solution [23].

PSO consist of two main operators that is updating the speed and updating the position. Every generation contain the particle that can be accelerated to the best position of population (global best) [24]. The updated velocity in each iteration for every particle is calculated based on the velocity at current iteration, the distance of best previous position, and the distance from the best global position. Then, the new velocity is used to calculate the next position in the search space. This process will have repeated until the results reach the steady state position or achieve the limit iteration that predefined, therefore, it will find out the minimum error. The larger the population we used, the better solution we get. In this work, we use the 200 for population and 1000 for maximum iteration.

Estimation data that generated from data reconciliation is used to find out the existence of random error in measurement. In this case, it is assumed that measured data contain random error with unknown actual value which is caused by measuring instrument. Generally, random error is assumed to satisfy normal distribution with zero means with known standard deviation. In this study, we are going to calculate the standard deviation of measured data first. 
The application of PSO algorithm for data reconciliation is done by thermodynamics calculation that must be satisfy the mass and energy balance on the fluid flow. The calculation is started from preheater to HPSH 2 for cold fluid and HPSH 2 to preheater for hot fluid.

\section{E. Gross Error Detection}

Real-time measurement on the power plant is contain random error and gross error, as stated in equation (4). The impact of existence of random error and gross error is increasing the uncertainty of monitoring result on power plant performance [31,32].

$$
\mathbf{y}=x+e_{s}+\varepsilon
$$

\section{Where is}

y : Observed value of the raw measurement

$x$ : True/actual value of the process variable

$e_{s}:$ Random error

$\varepsilon \quad:$ Gross error

Based on equation (4), information about uncertainty/inaccuracy of process data that contain random error and gross error is obtained from raw measurement. The exixtence of random error have bigger possibility than gross error on measurement [1].

Random error is an error which happens in repeated measurements of the same instrument and identical conditions that resulting different data measurements. Meanwhile, gross error is an error caused by a non-random event in repeated measurements of the same instrument and identical conditions that resulting same data measurements.

The method that used to detect gross error is statistical hypothesis method. Gross error is declared with statistical test model that must be able to identify type, location, and quantity of gross error. In this work, we use Global Test to detect gross error using the following equation:

$$
\gamma_{R}=\mathbf{r}^{T} K \mathbf{r}=(\mathbf{M x}-\mathbf{D})^{T}\left(\mathbf{M} \Sigma \mathbf{M}^{T}\right)^{-1}(\mathbf{M x}-\mathbf{D})
$$

Where $\mathbf{M}, \mathbf{D}$ are matrix generation of data reconciliation result. $\gamma_{\mathrm{R}}$ is chi square distribution with vector $\mathbf{r}$ that obtained when substituting the reconcilition result on the constraint with measured result, and the number of row for the residual vector in the measured data, i.e. $m-p$. If there are not gross errors in measurement, statistic test $\gamma_{R}$ will follow chi squares distribution with degree of freedom $v=$ $m-p$. There is a criterion that used to determine the existence of gross error on measurement. The criterion $x_{1-\alpha, m-p}^{2}$ is the critical value of chi squared distribution at the chosen level significance $x_{(1-\alpha)}^{2}$. The criterion is:

- If $\gamma_{\mathrm{R}}$ is equal to or greather than test criterion $x_{1-\alpha, m-p}^{2}$, the gross error will be detected on the measurement

- If $\gamma_{\mathrm{R}}$ is smaller than $x_{1-\alpha, m-p}^{2}$, the gross error will not be detected on the measurement.

The significance level of $\alpha$ that used is 5\%. Thus, if there is no gross in measured data, the probability of a statistical test becomes greather than the criterion test is equal to or less than $5 \%$. Indication of gross error in measurement data will reduce the reliability of data reconciliation results. If there is gross error in measurement, so we should detect, identify, and eliminate the gross error.

\section{RESULT AND ANALYSIS}

\section{A. Data Reconciliation}

Based on the calculation of $\mathrm{Q}_{\mathrm{H}}$ and $\mathrm{Q}_{\mathrm{C}}$ for unmeasured variable on heat exchanger component, it can be confirmed that it does not satisfy the mass and energy balance, and as a result, data reconciliation must be done. The result of data reconciliation is repeated in each iteration, where in each iteration looking for the best solution to generate estimated value.

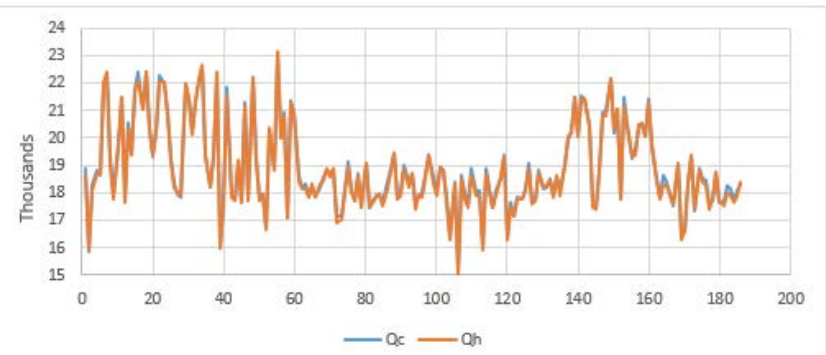

Figure 2. The value of data reconciliation for $\mathrm{Q}_{\mathrm{H}}$ and $\mathrm{Q}_{\mathrm{C}}$ in preheater

Based on Figure 2, the result of data reconciliation is showed that the heat energy flow of cold and hot fluid has the same value on each component, therefore, it can reach balance condition.

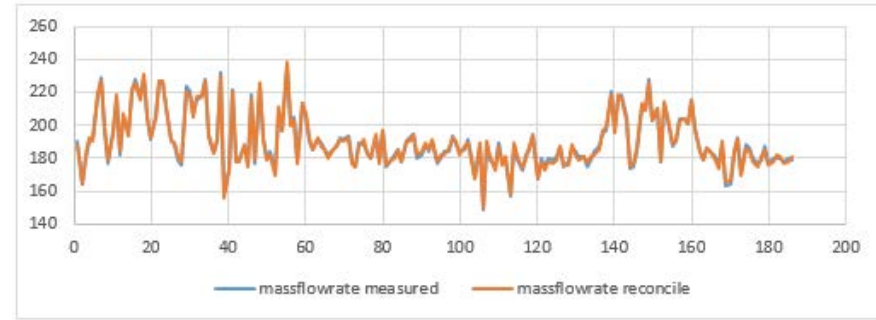

(a)

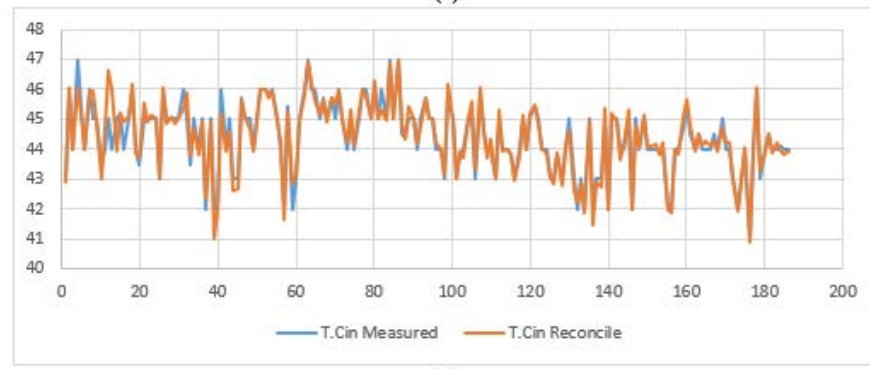

(b)

Figure 3. The result of data reconciliation for (a) mass flow rate and (b) temperature outlet for cold fluid in preheater

Figure 3 shows that the result of data reconciliation for mass flow rate and temperature of preheater have a small error value. It also can be seen in Table 3. In this case, PSO algorithm is capable in minimizing error with maximum tolerance of $5 \%$ for mass flow rate and must satisfy the law of mass and energy balance as a constrain.

Based on Table 3, it shows the differences between average measurement and the estimated data for mass flow rate of cold fluid is 0.14 . It means that there is random error in measurement. It is happened for several reason: fluctuation in power supply, transmission network, noise conversion signal, and others. The appearance of random error is beyond the control of the engineer, so it can not be eliminated and will always appear in every measurement. 
TABLE 3.

THE RESULT OF DATA RECONCILIATION ON PREHEATER

\begin{tabular}{llllll}
\hline \multirow{2}{*}{ Variable } & \multicolumn{2}{c}{ Measured } & \multicolumn{2}{c}{ Reconciled } & \multirow{2}{*}{ Error } \\
\cline { 2 - 5 } & Mean & St.Dev & Mean & St.Dev & \\
\hline Flow in COLD & 190.55 & 16.28 & 190.41 & 16.29 & 0.01 \\
Temp. Cold In & 44.40 & 1.15 & 44.42 & 1.20 & 0.09 \\
Temp. Cold Out & 135.70 & 0.75 & 135.73 & 0.69 & 0.05 \\
Temp. Hot In & 160.94 & 2.14 & 161.06 & 2.12 & 0.05 \\
Temp. Hot Out & 123.89 & 3.34 & 123.93 & 3.33 & 0.01 \\
\hline \hline
\end{tabular}

The aim of data reconciliation is to reduce imprecision and unreliability of data measurements by minimizing the error. In this case, this study apply Particle Swarm Optimization (PSO) algorithm. In the previous explanation, it has been described that PSO is capable to minimizing error for this plant. Table 4 below shows the SSE on each component of heat exchanger.

TABLE 4.

THE SUM SQUARE ERROR CALCULATION RESULT USING PSO

\begin{tabular}{lccccc}
\hline \hline Component & $\mathbf{e}-\boldsymbol{m}_{\mathbf{C}}$ & $\mathbf{e}-\mathbf{T}_{\text {C.in }}$ & $\mathbf{e}-\mathbf{T}_{\text {C.out }}$ & $\mathbf{e}-\mathbf{T}_{\text {H.in }}$ & $\mathbf{e}-\mathbf{T}_{\text {H.out }}$ \\
\hline Preheater & 0.010 & 0.088 & 0.112 & 0.047 & 0.014 \\
LP Eco & 0.012 & 0.169 & 0.041 & 0.026 & 0.024 \\
HP Eco 1 & 0.015 & 0.117 & 0.070 & 0.028 & 0.018 \\
LP Eva & 0.017 & 0.039 & 0.008 & 0.017 & 0.027 \\
HP Eco 2 & 0.018 & 0.091 & 0.007 & 0.008 & 0.024 \\
HP Eva & 0.016 & 0.001 & 0.006 & 0.014 & 0.005 \\
HPSH 1 & 0.016 & 0.001 & 0.000 & 0.002 & 0.001 \\
HPSH 2 & 0.022 & 0.008 & 0.008 & 0.002 & 0.002 \\
\hline \hline
\end{tabular}

Based on Table 4, we can see that PSO algorithm shows a minimum error for each component in variable reconciliation. It means that PSO is a compatible algorithm for the instrument system on PLTGU Gresik that can minimize error, that is 1.153 .

\section{B. Gross Error Detection}

Data reconciliation and gross error detection are performed sequentially. Gross error detection must be done with statistical hypothesis method, that is Global Test. The result of calculation is showed in Table 4. The value of degree of freedom is generated from the criterion value of chi square distribution table, that the value is 4 . Based on the critical value on significance level $\alpha$ of $5 \%$, thus the value of criterion chi square based on table chi square $x^{2}{ }_{1}$ $5 \%, 4=9.488$.

TABLE 5.

THE RESULT OF GROSS ERROR DETECTION

\begin{tabular}{llllll}
\hline \hline Component & $\boldsymbol{\gamma}_{\mathrm{R}} \boldsymbol{m}_{\mathrm{C}}$ & $\boldsymbol{\gamma}_{\mathrm{R}} \mathbf{T}_{\mathrm{C} \text {.in }}$ & $\boldsymbol{\gamma}_{\mathrm{R}} \mathbf{T}_{\text {C.out }}$ & $\boldsymbol{\gamma}_{\mathrm{R}} \mathbf{T}_{\mathbf{H . i n}}$ & $\boldsymbol{\gamma}_{\mathrm{R}} \mathbf{T}_{\mathbf{H . i n}}$ \\
\hline Preheater & 2.6 & 0.5 & 0.1 & 0.3 & 0.2 \\
LP Eco & 1.145 & 0.054 & 0.667 & 0.14 & 0.122 \\
HP Eco 1 & 2.597 & 0 & 0.621 & 0.154 & 0.99 \\
LP Eva & 1.137 & 0.639 & 0.702 & 0.132 & 0.1 \\
HP Eco 2 & 3.053 & 0.811 & 0.818 & 0.255 & 0.194 \\
HP Eva & 2.743 & 0.133 & 0.704 & 0.534 & 0.193 \\
HPSH 1 & 2.738 & 0.126 & 0.085 & 0.175 & 0.18 \\
HPSH 2 & 2.699 & 1.923 & 2.035 & 0.154 & 0.189 \\
\hline \hline
\end{tabular}

Table 4 shows that the calculation result based on chi square distribution is lower than the criterion value based on chi square table, $\gamma_{R} \leq x^{2}{ }_{1-5 \%, 4}$, it means no gross error on measurement on PLTGU Gresik, thus the data reconciliation calculation results are validated. It can be implied that PLTGU Gresik was calibrate the instrument frequently, so that have a good performance and can generate optimal eficiency with consider constrain, that is mass and energy balance

\section{CONCLUSION}

Data reconciliation is an efective method used to reduce the impact that arise when measurement error is occured. Based on the result of data reconciliation, balance condition can be reached by satisfying the mass and energy balance as a constrain. It can generate reliable estimating data on data reconciliation. Reliable estimating data has a maximum tolerance for temperature and mass flow rate that is $1^{\circ}$ and $5 \%$. Those maximum tolerance can generate small error. It can be seen by perform a calculation that uses sum square error on five variable reconciliation in each component of heat exchanger. In this case, PSO algorithm as a nondeterministic optimization method is capable to generate reliable data and minimizing error by satisfying mass and energy balance as constraint.

Based on the result of data reconciliation, the value of standard deviation for measurement data is different to the value of standard deviation for the result of data reconciliation. It this case, data reconciliation can improve data reliability on five variable reconciliation efficienly that following normal distribution. Based on this differences, we know that there is random error on the measurement data in PLTGU Gresik. Random error can be arise for several reason: fluctuation in power supply, transmission network, noise conversion signal, and others.

There is not gross error on the measurement data in PLTGU Gresik. It can be confirmed from the value of critical based on chi square distribution that is smaller than the criterion value based on chi square table $\left(\gamma_{R} \geq x^{2}{ }_{1-5 \%, 4}\right)$. Because there is not gross error in the measurement, so that the instrument in PLTGU Gresik have a good performance and can generate optimal eficiency with consider constrain, that is mass and energy balance..

\section{REFERENCES}

[1] Z. Zhang and J. Chen, "Correntropy based data reconciliation and gross error detection and identification for nonlinear dynamic processes,” Comput. Chem. Eng., vol. 75, pp. 120-134, Apr. 2015.

[2] É. Poulin, D. Hodouin, and L. Lachance, "Estimation of Measurement Error Variances in Data Reconciliation Using a Flow Distribution Model," in 15th IFAC Symposium on System Identification, 2009, vol. 42, pp. 976-981.

[3] A. Vasebi, É. Poulin, and D. Hodouin, "Selecting proper uncertainty model for steady-state data reconciliation - Application to mineral and metal processing industries,” Miner. Eng., vol. 65, pp. 130-144, Oct. 2014.

[4] S. Sunde and Ø. Berg, "Data reconciliation and fault detection by means of plant-wide mass and energy balances," Prog. Nucl. Energy, vol. 43, no. 1-4, pp. 97-104, Jan. 2003.

[5] M. Langenstein, "Power Recapture and Power Uprate in NPPS with Process Data Reconciliation in Accordance with VDI 2048,” in 14th International Conference on Nuclear Engineering, 2006, pp. 1-8.

[6] E. D. Valdetaro and R. Schirru, "Simultaneous Model Selection, 
Robust Data Reconciliation and Outlier Detection with Swarm Intelligence in a Thermal Reactor Power calculation,” Ann. Nucl. Energy, vol. 38, no. 9, pp. 1820-1832, Sep. 2011.

[7] A. Martini, A. Sorce, A. Traverso, and A. Massardo, "Data Reconciliation for power systems monitoring: Application to a microturbine-based test rig,” Appl. Energy, vol. 111, pp. 11521161, Nov. 2013.

[8] X. Jiang, P. Liu, and Z. Li, "Data reconciliation and gross error detection for operational data in power plants,” Energy, vol. 75, pp. 14-23, Oct. 2014.

[9] F.-G. Liu, X.-T. Wang, X.-H. Su, and W.-X. Tao, Detection and reconciliation on the abnormal operation data based on redundancy measurement in a power plant, vol. 23. 2003.

[10] W. Zhou, Z. Qiao, J. Zhou, F. Si, and Z. Xu, A simultaneous data reconciliation and gross error detection method for thermodynamic systems, vol. 32. 2012.

[11] R. Maronna and J. Arcas, "Data reconciliation and gross error diagnosis based on regression,” Comput. Chem. Eng., vol. 33, no. 1, pp. 65-71, Jan. 2009.

[12] D. M. Prata, M. Schwaab, E. L. Lima, and J. C. Pinto, "Simultaneous robust data reconciliation and gross error detection through particle swarm optimization for an industrial polypropylene reactor,” Chem. Eng. Sci., vol. 65, no. 17, pp. 4943-4954, Sep. 2010.

[13] K. Morad, W. Y. Svrcek, and I. McKay, “A robust direct approach for calculating measurement error covariance matrix," in Proceedings of the 1999 American Control Conference (Cat. No. 99CH36251), 1999, pp. 3275-3279 vol.5.

[14] J. Y. Keller, M. Zasadzinski, and M. Darouach, “Analytical estimator of measurement error variances in data reconciliation,” Comput. Chem. Eng., vol. 16, no. 3, pp. 185-188, Mar. 1992.
[15] J. Chen, A. Bandoni, and J. A. Romagnoli, "Robust estimation of measurement error variance/covariance from process sampling data,” Comput. Chem. Eng., vol. 21, no. 6, pp. 593-600, Feb. 1997.

[16] N. Arora and L. T. Biegler, "Redescending estimators for data reconciliation and parameter estimation,” Comput. Chem. Eng., vol. 25, no. 11-12, pp. 1585-1599, Nov. 2001.

[17] S. Narasimhan and C. Jordache, Data reconciliation \&amp; gross error detection : an intelligent use of process data. Houston, Texas: Gulf Publishing Company, 2000.

[18] S. Guo, P. Liu, and Z. Li, "Data reconciliation for the overall thermal system of a steam turbine power plant,” Appl. Energy, vol. 165, pp. 1037-1051, Mar. 2016.

[19] C. Reimers, J. Werther, and G. Gruhn, "Flowsheet simulation of solids processes: Data reconciliation and adjustment of model parameters,” Chem. Eng. Process. Process Intensif., vol. 47, no. 1, pp. 138-158, Jan. 2008.

[20] F. Manenti, M. G. Grottoli, and S. Pierucci, "Online Data Reconciliation with Poor Redundancy Systems,” Ind. Eng. Chem. Res., vol. 50, no. 24, pp. 14105-14114, Dec. 2011.

[21] J. Kennedy and R. Eberhart, "Particle swarm optimization," in Proceedings of ICNN'95 - International Conference on Neural Networks, 1995, vol. 4, pp. 1942-1948.

[22] C. Blum and X. Li, "Swarm Intelligence in Optimization," in Swarm Intelligence, Berlin, Heidelberg: Springer Berlin Heidelberg, pp. 43-85.

[23] M. Settles, “An Introduction to Particle Swarm Optimization,” University of Idaho, 2005.

[24] J. Smrekar, M. Assadi, M. Fast, I. Kuštrin, and S. De, "Development of artificial neural network model for a coal-fired boiler using real plant data,” Energy, vol. 34, no. 2, pp. 144-152, Feb. 2009. 